\title{
Neutronics Verification of GA Accelerator Transmutation of Waste Concept
}

\author{
By
}

\author{
Yousry Gohar, Temitope A. Taiwo*, and Phillip J. Finck \\ Technology Development Division \\ ${ }^{*}$ Reactor Analysis and Engineering Division \\ Argonne National Laboratory \\ 9700 South Cass Avenue \\ Argonne, IL 60439
}

Work supported by the Office of Fusion Energy Sciences

U.S. Department of Energy Under Contract W-31-109-Eng-38 


\section{Table of Contents}

$\underline{\text { Page }}$

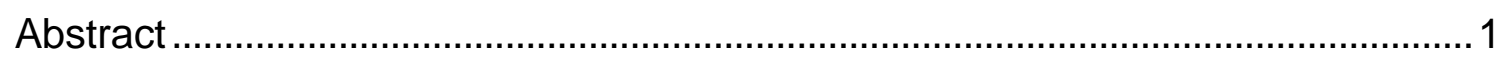

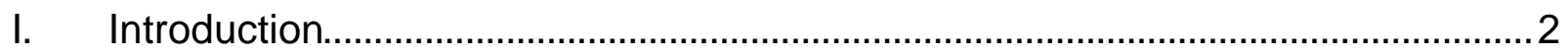

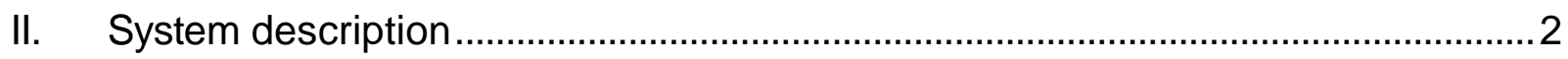

III. Computational models and computer codes ........................................................ 3

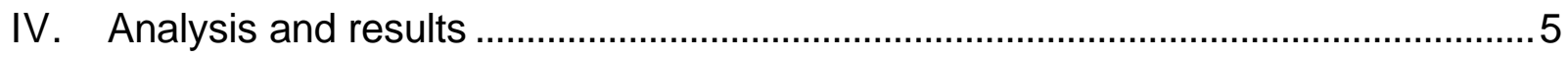

IV.1. TRU material heterogeneity effect.................................................... 5

IV.2. Burnable poison heterogeneity effect …………………………........... 6

IV.3. Cross-section library choice effect ……….............................................

IV.4. Temperature effect..........................................................................

IV.5. Block power distribution ..................................................................

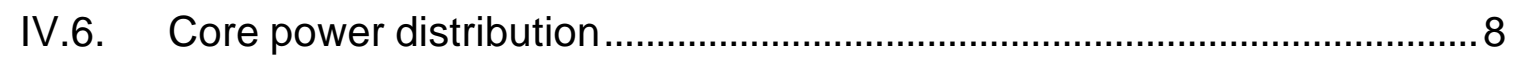

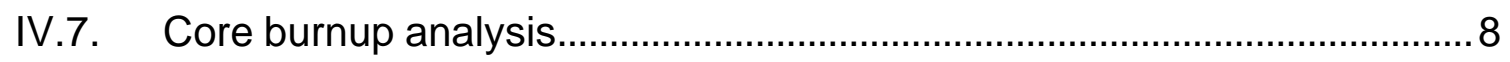

IV.8. Block sensitivity to TRU and BP material loading parameters ................. 9

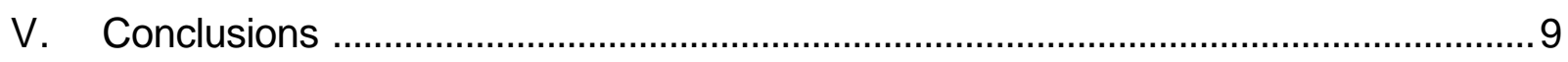

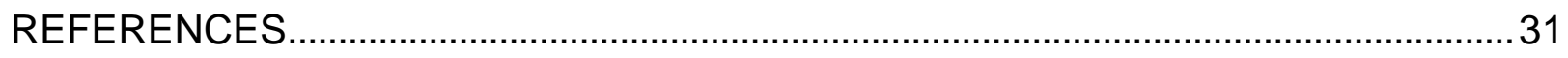




\section{List of Figures}

Figure No.

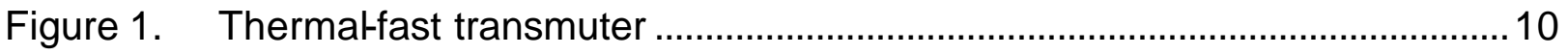

Figure 2. Thermalfast transmuter cross section..................................................... 11

Figure 3. TRU particle, fuel compact, and thermal block ............................................ 12

Figure 4. Cross-sectional view of the thermal block ....................................................13

Figure 5. Thermal block model featuring coolant channels (Black color), fuel compacts (Yellow color), and burnable poison compacts (White color)

Figure 6. Enlarged block section featuring a section of the coolant channel, fuel compact, and burnable poison compact

Figure 7. TRU particle model showing the five materials of each particle, transuranic oxide, porous carbon buffer, Inner pyrolytic carbon, silicon carbide, and outer pyrolytic carbon .................................................. 16

Figure 8. Horizontal cross section of the MONK transmuter model...........................17

Figure 9. Enlarged section of the MONK transmuter model......................................18

Figure 10. Main burnup parameters as a function of the operating time for different burnup intervals

Figure 11. Relative atomic concentrations of the plutonium isotopes as a function of the operating time

Figure 12. Relative atomic concentrations of the americium and curium-244 isotopes as a function of the operating time

Figure 13. Relative atomic concentrations of the erbium isotopes as a function of the operating time

Figure 14. Block $\mathrm{K}_{\infty}$ as a function of the fuel-packing factor for different burnable poison packing factors 


\section{List of Tables}

Table No.

Page

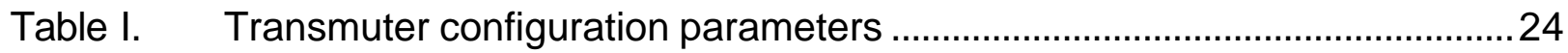

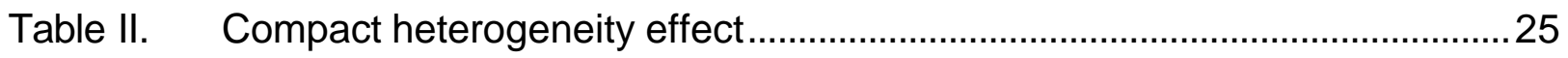

Table III. MONK burnable poison heterogeneity effect …………………….............26

Table IV. Impact of different nuclear data libraries on monk block results .................22

Table V. Temperature effect on the block performance ............................................28

Table VI. Percentage differences in the compact power distribution from DRAGON and MONK relative to MONK results for half block...

Table VII. Core power distribution and the percentage differences between DRAGON and MONK relative to MONK results for sixty-degree sector 30 


\begin{abstract}
An assessment has been performed for an Accelerator Transmutation of Waste (ATW) concept based on the use of the high temperature gas reactor technology. The concept has been proposed by General Atomics for the ATW system. The concept uses recycled light water reactor (LWR)-discharge-transuranic extracted from irradiated oxide fuel in a critical and sub-critical accelerator driven gas-cooled transmuter. In this concept, the transmuter operates in the critical mode for three cycles and then operates in a subcritical accelerator-driven mode for a single cycle. The transmuter contains both thermal and fast spectrum transmutation zones. The thermal zone is fueled with the transuranics (TRU) oxide material in the form of coated particles, which are mixed with graphite powder, packed into cylindrical compacts, and loaded in hexagonal graphite blocks with cylindrical channels. The fast zone is fueled with TRU-oxide material in the form of coated particles without the graphite powder and the graphite blocks that has been burned in the thermal region for three critical cycles and one additional accelerator-driven cycle. The fuel loaded into the fast zone is irradiated for four additional cycles. This fuel management scheme is intended to achieve high plutonium consumption in the thermal spectrum zone, and to consume the minor actinides in the fast-spectrum zone.
\end{abstract}

The Monte Carlo code MONK has been used for accurately analyzing the thermal transmuter performance, which is the subject of this report. A special attention was given for the development of accurate calculational models to account for the geometrical details and to assess the corresponding heterogeneity effects. The block geometry has several levels of heterogeneity that require proper treatment to predict the system performance. Another geometrical heterogeneity is also present because of the annular transmuter configuration that employs inner and outer reflector zones. Accurate explicit geometrical models were developed and used to assess the system performance. Both JEF2.2 and ENDF/B-VI nuclear data libraries were used in two forms: quasi-continuous energy representations (13193 or 8220 groups) and conventional multi-group libraries (172 or 69 groups). Also, the integrated burn-up capability of the MONK code was utilized to determine the feasibility of achieving high TRU consumption levels.

The report describes the transmuter and the major design parameters that can be altered to optimize the system design. Also, the Monte Carlo models and the neutronics studies are presented and discussed. The results from the parametric studies of the fuel block and the whole transmuter to understand the physics and the design performance are presented including the power distribution for the fuel block and the transmuter, and the detailed burn-up analysis. In addition, the Monte Carlo results are used to validate the analyses performed with deterministic method. 


\section{Introduction}

A thorough neutronic assessment of the Accelerator Transmutation of Waste (ATW) concept that uses the high temperature gas reactor technology has been performed. The concept was proposed by General Atomics [1]. This concept uses recycled transuranic (TRU) materials extracted from spent fuels, in a critical and subcritical accelerator driven gas-cooled transmuter. The spent fuels were discharged from light water reactors (LWR). In this concept, the transmuter operates in the critical mode for three cycles and then operates in a subcritical accelerator-driven mode for a single cycle. The transmuter contains both thermal and fast spectrum transmutation zones. The thermal zone is fueled with the TRU oxide materials in the form of coated particles, which are mixed with a graphite powder, packed into cylindrical fuel compacts, and loaded in hexagonal graphite blocks with cylindrical channels. The fast zone is fueled with the same fuel particles extracted from the cylindrical compacts that has been irradiated in the thermal region for three critical cycles and an additional acceleratordriven cycle without the graphite powder. This fuel management scheme is intended to consume most of the plutonium $(\mathrm{Pu})$ isotopes in the thermal-spectrum zone and the minor actinides in the fast-spectrum zone [2, 3, and 4].

In this assessment, a special attention was given for developing accurate detailed geometrical models for the thermal block and the whole transmuter. These models were used to assess the physics characteristics including the heterogeneity effects, to perform parametric studies for understanding and optimizing the transmuter performance, and to verify the physics predictions obtained by the deterministic methods [5]. The thermal block geometry has several levels of heterogeneity that require proper treatment to predict the system performance. Another geometrical heterogeneity is also present in the system because of the annular configuration that employs inner and outer reflector zones. The MONK Monte Carlo code [6] has been used to get an accurate explicit geometrical modeling and to assess the system performance. Both JEF2.2 and ENDF/B-VI nuclear data libraries were used in two forms: quasi-continuous energy representations (13193 or 8220 groups) and conventional multi-group libraries (172 or 69 groups). Also, the integrated burn-up capability of the MONK code was used to determine the feasibility of achieving high TRU consumption levels.

The results from the thermal block and the whole transmuter parametric studies are presented including power distribution and the detailed burn-up analysis. Also, the results from the deterministic calculations were compared to MONK results.

\section{System description}

The transmuter consists of a steel vessel housing, containing an annular transmutation region operating with a thermal neutron spectrum. This annular region contains the "fresh" TRU separated from light water reactor spent fuels. A general layout of the system proposed by GA is shown in Figures 1 and 2. The TRU materials are contained in spherical TRISO-coated particles. These spherical particles consist of 
a 200- $\mu \mathrm{m}$ diameter TRUO ${ }_{1.7}$ core, called kernel, surrounded by layers of graphite buffer $(100-\mu \mathrm{m})$ to absorb gaseous fission products, pyrolitic graphite $(35-\mu \mathrm{m})$, silicon carbide $(35-\mu \mathrm{m})$ to serve as a stable barrier and pressure vessel, and an outside layer of pyrolitic graphite $(40-\mu \mathrm{m})$. These particles are mixed with graphite powder and packed into cylindrical fuel compacts. The compacts are loaded into cylindrical channels within hexagonal graphite blocks. Figure 3 shows the TRU particle details, fuel compacts, and a thermal block. These blocks also have channels for helium coolant flow and channels for introducing erbium burnable poison into the system. The block is $36 \mathrm{~cm}$ flat-to-flat, and contains 202 fuel channels, 108 coolant channels, and 14 burnable poison (BP) channels. All the channels are arranged on a $1.88-\mathrm{cm}$ triangular pitch as shown in figure 4. The fuel blocks are loaded into the fifth, the sixth, and the seventh radial rings of a hexagonal configuration. Three rings of graphite reflector are arranged both inside and outside this thermal region. The innermost layer is filled with fast fuel assemblies, composed of the TRU particles that have undergone four years of burning in the thermal region of the transmuter. The vertical configuration comprises ten active blocks stacked vertically. At the center of the configuration is the location for a spallation target used during the period of subcritical operation.

The transmuter operates in the critical mode for approximately three years. In this mode, the critical thermal region drives the fission process and very limited transmutation events are expected in the fast region. After these three years, the thermal region becomes subcritical and is driven by the spallation neutrons during the fourth year of the cycle. The local multiplication of spallation neutrons in the fast region produces a significant fast flux thus helping the transmutation of the minor actinides. The plant has four $600 \mathrm{MW}_{\text {th }}$ transmuters, sharing one 15-MW beam accelerator.

The transmuter is cooled by helium with an outlet temperature of $850{ }^{\circ} \mathrm{C}$. The heated helium is used in a direct-cycle gas-turbine-generator system. The high helium operating temperature and the utilization of the direct Brayton power conversion system allow electric generation with a high net thermal efficiency of about $47 \%$.

\section{Computational models and computer codes}

As aforementioned, the transmuter design includes several levels of heterogeneity effects that require proper treatment to obtain accurate performance predictions. The transmuter geometry consists of hexagonal prismatic blocks of graphite containing parallel vertical holes, arranged in a triangular pitch. These holes contain fuel or BP compacts and some vacant holes for helium colant flow paths. The fuel and the BP compacts consist of multi-layer ceramic-coated particles dispersed in a graphite matrix. Significant neutronics heterogeneities are created by these small particles. Block heterogeneity arises from the heterogeneous arrangement of fuel, BP, and coolant channels in the graphite block. Another geometrical heterogeneity is due to the annular configuration that employs inner and outer reflector zones. 
An explicit detailed model for the block was developed using the MONK computer code. MONK has the capability to explicitly model the geometry under consideration and to perform criticality and burnup analyses in an integrated manner. The particles are modeled as a hexagonally close-packed lattice of spheres. The lattice forms a regular octahedron with a cylindrical boundary to represent the compact. MONK criticality calculations were performed with quasi-continuous energy and multigroup data sets. The quasi-continuous energy data sets are processed in a fine energy mesh (13193 or 8220 groups). The multigroup libraries are processed in a much coarser set (172 or 69 groups). The burnup analyses use the coarser data sets. The nuclear data libraries are based on JEF version 2.2 or ENDF/B-VI.

Three MONK models were developed for the heterogeneity analyses. These are:

- An explicit block model with explicit representation of the multi-layers of the TRU and the BP particles inside the compacts,

- A block model with homogenized particles inside the compacts, and

- A block model with homogenized compacts inside the block.

Table 1 and Figure 4 gives the data and the geometry that are used to generate the MONK block models. Figure 5 shows the explicit MONK block model and an enlarged section is shown in Figure 6. The explicit TRU particle model is shown in Figure 7.

Also, a three-dimensional transmuter model was developed for performing the neutronics analyses using the MONK code. The model has explicit representation for the TRU and the burnable poison particles including all the geometrical details. The blocks are located in rings six to eight. Rings one to five and nine to eleven contain graphite reflector blocks. Axially, the whole length of the active core $(793 \mathrm{~cm})$, and additional lower and upper graphite reflector blocks are modeled. A vacuum boundary condition is used for all external surfaces. A cylindrical boundary is used for the radial reflector to match the actual configuration. A horizontal cross section of the model is shown in Figure 8 and an enlarged section in Figure 9 where all the explicit geometrical details were preserved.

Two independent computational paths have been implemented for the analyses:

- An independent stochastic path based on MONK computer code has been utilized. It is also used to check the predictions of the deterministic path and to provide a reference database. The MONK capabilities to explicitly model the geometry under consideration and to perform criticality and burnup analyses in an integrated manner were utilized.

- A deterministic path based on the DRAGON [7], DIF3D [8], and REBUS [9] computer codes has been utilized. It promises fast computer running times but it relies on a series of energetic and spatial homogenization steps, which might decrease the accuracy of the results. Thus, it needs to be carefully validated. Burnup-dependent, 
block-average microscopic cross-sections are obtained using the DRAGON lattice computer code and an ENDF/B-VI based 69-group library. The DRAGON computer code is selected because it models accurately the dispersion fuel in a graphite matrix and permits full-block calculations using the collision probability method. Resonance self-shielding and depletion calculations in the particles are possible because DRAGON allows explicit representations of the multi-layer TRU and BP particles, the matrix graphite, and the block graphite of the transmuter.

\section{Analysis and results}

Several block and full transmuter analyses were performed to study and to define the impact of the different design parameters on the transmuter performance. The analyses include the TRU material heterogeneity effect, the burnable poison heterogeneity effect, the cross-section library choice effect, the temperature effects, the block power distribution, the core power distribution, and burnup analysis. The results are presented and discussed in this section.

\section{IV.1. TRU material heterogeneity effect}

The block $k_{\infty}$ values obtained from the second and the third geometrical models relative to the first geometrical models, defined in section III, are indicative of the heterogeneity effect. Table II summarizes the MONK results, which were obtained with the use of the 13193-groups quasi-continuous energy and the 172-groups nuclear data libraries based on JEF2.2. The DRAGON results are also given in Table II.

In these analyses, the block is loaded with fuel compacts and helium coolant channels and the erbium burnable poison compacts were replaced with fuel compacts. The volume packing fraction for the TRU particles is 0.1238 . The heavy-metal loading is 771 grams per block at room temperature. The composition and density of each material in the block are given in Table I. The results show a strong heterogeneity effect of $\sim 14 \%$, see Table II. The difference in the results between quasi-continuous energy libraries and the multigroup libraries is due to the difference in thermal treatment of the carbon nuclear data. The quasi-continuous energy libraries are lacking the $S(\alpha, \beta)$ treatment for carbon.

The homogeneous models give inaccurate $k_{\infty}$ values because these models significantly underestimate the self-shielding of the strong absorption resonances in the plutonium isotopes, particularly Pu-240. This is caused by the fact that the fuel particle dimensions are relatively large compared to the mean free path of neutrons in the lowenergy-lying resonances of these isotopes. Because of this effect, the inner zone of the particle is shielded from neutrons by the outer zone and simple homogenization does not account correctly for the self-shielding effect. 
The DRAGON results show the same heterogeneity effect similar to MONK. In addition, the results obtained from both codes show an excellent agreement for the explicit and the homogenized models as shown in Table II.

\section{IV.2. Burnable poison heterogeneity effect}

Heterogeneity analyses were performed for the BP particles and the results are given in Table III. The volume packing fractions for the TRU and the BP particles are 0.1238 and 0.1 , respectively. The MONK computer code with the quasi-continuous energy nuclear library (13193 groups) based on JEF2.2 was used for the analysis. Similar to the TRU analysis, three cases were analyzed for the BP. The particle homogenization underestimates the $\mathrm{k}_{\infty}$ by about $-1.8 \%$ relative to the explicit modeling as shown in Table III. The homogenized compact increases the difference to $-2.2 \%$. These results are consistent with the TRU heterogeneity results obtained before. In this case, the self-shielding change caused by the erbium absorption resonance explains the change in $k_{\infty}$ of the block, which discussed further in the next paragraph. The burnable poison heterogeneity effect is smaller than the corresponding value for the TRU because the block has only 14 BP compacts relative to 202 fuel compacts.

The homogeneous models give inaccurate $k_{\infty}$ values because these models significantly under predict the self-shielding of the strong absorption resonances of Er167 in the BP. This is caused by the fact that the BP particle dimensions are relatively large compared to the mean free path of neutrons in the low-energy-lying resonances of ER-167. Because of this effect, the inner zone of the particle is shielded from neutrons by the outer zone and simple homogenization of cross sections does not account correctly for the self-shielding effect.

For both the TRU and BP cases, the heterogeneity effect was found to be dependent on the particle composition and the compact packing fraction because of the changes in the neutron spectrum. The difference in $k_{\infty}$ between the romogeneous and explicit models decreases as the packing fraction increases for fixed particle size or as the fuel radii decreases for fixed packing fraction.

\section{IV.3. Cross-section library effect}

The detailed geometrical model used to study the TRU heterogeneity effect is used with different nuclear data libraries to investigate any effect on the predicted performance. In this analysis, the block is loaded with fuel compacts and helium coolant channels and the erbium burnable poison compacts are replaced with fuel compacts. The volume packing fraction for the TRU particles is 0.1238 . The heavy-metal loading is 771 grams per block. The composition and density of each material in the block are given in Table I. Five data libraries based on JEF2.2 and ENDF/B-VI are used as shown in Table IV. 
The first two results were obtained with the 13193-groups quasi-continuous energy data sets based on ENDF/B-VI and JEF2.2 as shown in Table IV. The obtained results for these two cases are identical. Therefore, the choice of either database does not impact the results and it provides confidence in the obtained results. The second and third results were calculated with different quasi-continuous energy data sets based on JEF2.2 as shown in Table IV. Again the results show an excellent agreement.

The last two results in Table IV were calculated with multigroup data sets based on JEF2.2. These results are in good agreement but they are different from the previous three results. The difference is due to the difference in thermal treatment of the carbon nuclear data as mentioned before. The quasi-continuous energy libraries are lacking the $S(\alpha, \beta)$ treatment for carbon. All these results show that both ENDF/B-VI and JEF2.2 provides similar results for the block analysis and $S(\alpha, \beta)$ treatment for carbon has impact on the results.

\section{IV.4. Temperature effect}

One important feature of this transmuter is the negative temperature coefficient. As the transmuter temperature increases, the neutron spectrum peak shifts toward the absorption resonance of erbium-167. This results in more neutron absorption in erbium167. The analysis was performed in steps to define the contribution of each material to this effect using the explicit MONK model with the 172-groups nuclear data library. In this case, the packing fractions are 0.15 and 0.1 for the TRU and the BP, respectively. The first case has all the materials at $293.16 \mathrm{~K}$. In the second case, the TRU particle temperature was changed to the average operating temperature without changing the temperature of the other materials. The third case is similar to the second case with the graphite temperature of the compact changed to average operating temperature. The last case changed the graphite block temperature to the operating temperature. Table $\mathrm{V}$ shows the results for these cases. Heating the block materials increases the neutron absorption in erbium-167, which results in a negative temperature coefficient. This enhances the safety performance of the system.

\section{IV.5. Block power distribution}

The block power distribution was also calculated using the explicit MONK model at the cold state $(293.16 \mathrm{~K})$. The maximum power occurs in a TRU compact located close to the block boundary because of the extra (non-cell) graphite present in this zone, which causes a softer neutron spectrum. The peak value is 1.059 the average. The block power distribution has very little peaking due to the BP distribution in the block, which flattens the block power distribution. The minimum value is 0.963 the average and it is located in the fifth ring in the block.

The DRAGON code is also used to calculate the block power distribution and the

results are compared to the MONK results. Table VI shows the percentage differences 
in the compact power distribution relative to MONK Results. The power distribution results from both codes are in good agreement with a maximum difference of $2.9 \%$ observed at the center of the assembly. The difference in $\mathrm{K}_{\infty}$ between the two codes is $0.7 \%$.

\section{IV.6. Core power distribution}

The three-dimensional transmuter model was used to calculate the power distribution per block. The blocks have fresh fuel with a heavy metal loading of $787 \mathrm{~kg}$ and an Er-167 loading of $27.7 \mathrm{~kg}$. As mentioned before, the fuel blocks are located in rings six to eight. The results show that the peak power occurs in the sixth ring because of the central graphite reflector. The central graphite causes a softer neutron spectrum that enhances the fission rate. The peak to average is 1.22 as shown in Table VII for sixty-degree sector of the core. Similar to the block power distribution, the minimum power occurs in the middle fuel ring, ring number seven. The minimum power is 0.824 the average block power.

Similar results were obtained from DIF3D analysis as shown in Figure VII. The power distribution results from both codes are in good agreement with a maximum difference of $-1.7 \%$ observed at the outer fuel ring, which is shown is also shown in Table VII. The difference in $\mathrm{K}_{\infty}$ between the two codes is $0.42 \%$.

\section{IV.7. Core burnup analysis}

MONK burnup calculations were performed for the transmuter using the explicit geometrical model shown in Figure 8. The calculations were performed at the average operating temperatures of each material with the 172-groups nuclear cross section library based on JEF2.2. The fuel compact, the graphite block, and the reflector block temperatures are 1043.16, 993.16, and $993.16 \mathrm{~K}$, respectively. The explicit representation of the geometry was maintained in the burnup calculations. A constant fission power of $600 \mathrm{MW}$ was used in the calculations for 900 days. The packing factors for this configuration are 12.87 and $10 \%$ for the TRU and the BP, respectively.

The first step in this analysis was to define the appropriate time step (burnup interval) between subsequent flux calculations because of the large computer time required for each flux calculation. However, the use of a large time step reduces the accuracy of the results. A parametric study was performed to determine the effect of the time steps on the results. Several time steps were used as shown in Figure 10. The results show that the fresh transmuter has a K-effective of 1.1005. The K-effective drops to 1.0 after about 500 days. At 900 days, K-effective is very low for this configuration. The burnup parameters converge as the time step is reduced. The results from 12.5 and 25 days time steps are very close. About $44 \%$ of the TRU are burned in the first 500 days, and $80 \%$ are burned at 900 days. At a K-effective of 0.9 , the TRU burnup is $61 \%$. Er-167 is consumed at much faster rate as shown in Figures 
10 and 13. Only the Er-167 isotope is acting as a burnable poison and it is converted to Er-168, as shown in Figure 13. Further investigations are required to define the optimum TRU and Er packing factors to achieve 900 days of operation, if it is required, with adequate reactivity and Er-167 concentration for negative temperature coefficient during the critical operating period.

The changes in the atomic concentrations of the different TRU isotopes as a function of the operating time are shown in Figures 11 and 12. During the critical operation, Pu-239 decreases linearly with the operating time while Pu-240 decreases slowly. In the subcritical operation, the remaining Pu-239 decreases slowly while Pu240 decreases linearly with the operating time. Pu-241 increases to reach a peak value at about 380 days then it decreases linearly with the operating time. Pu-242 increases slowly during the operation. Pu-237 and Pu-238 decreases slowly during the operation.

Am-241 decreases linearly during the operation while Am-243 increases linearly. Am-242m and Cm-244 decrease slowly during the operation. Further analyses are required to define transmuter loading with TRU and BP materials and the fuel block parameters for optimum transmutation.

\section{IV.8. Block sensitivity to TRU and BP material loading parameters}

Several parametric studies were performed [10] to characterize the block reactivity. For example, Figure 14 shows the block $k_{\infty}$ as a function of the TRU-particle packing fraction for three different BP packing fractions, at the cold condition. The variation of $k_{\infty}$ versus the TRU packing fraction shows a peak at low TRU packing fraction. The shift in the neutron spectrum with the packing fraction is responsible for this trend. As the packing fraction decreases, the carbon-to-heavy-metal ratio increases and leads to an increase in the neutron thermalization causing the neutron spectrum to become softer. This result in fewer neutron captures, which enhances the neutron utilization. The improved utilization of neutrons increases Pu-239 fission rate, which enhances the $k_{\infty}$ as the TRU packing fraction decreases. The packing fraction corresponding to the highest $\mathrm{k}_{\infty}$ differs for the three curves. As the BP loading increases, the spectrum hardens due to the relative neutron absorption increase in Er-167 and Pur240. Also, less fuel material is required to achieve the same $k_{\infty}$. The $k_{\infty}$ increase with the TRU packing fraction, below the peak value of $k_{\infty}$, is due to the concentration increase of the fissile elements causing more fission reactions.

\section{Conclusions}

Several conclusions were obtained from this study. First, accurate geometrical models for Monte Carlo analyses were developed for the block and the whole transmuter based on the high temperature gas reactor technology with TRU in the form of coated particles. Second, these models were used successfully to perform detailed physics analyses including burnup. Third, the results show the need for using detailed geometrical 
models including explicit presentation for the multi-layers fuel particles because material homogenization introduces significant errors in the performance parameters. Fourth, the parametric studies show the potential for adjusting the block design to optimize the transmuter performance and the fuel cycle for achieving high transmutation rate. 


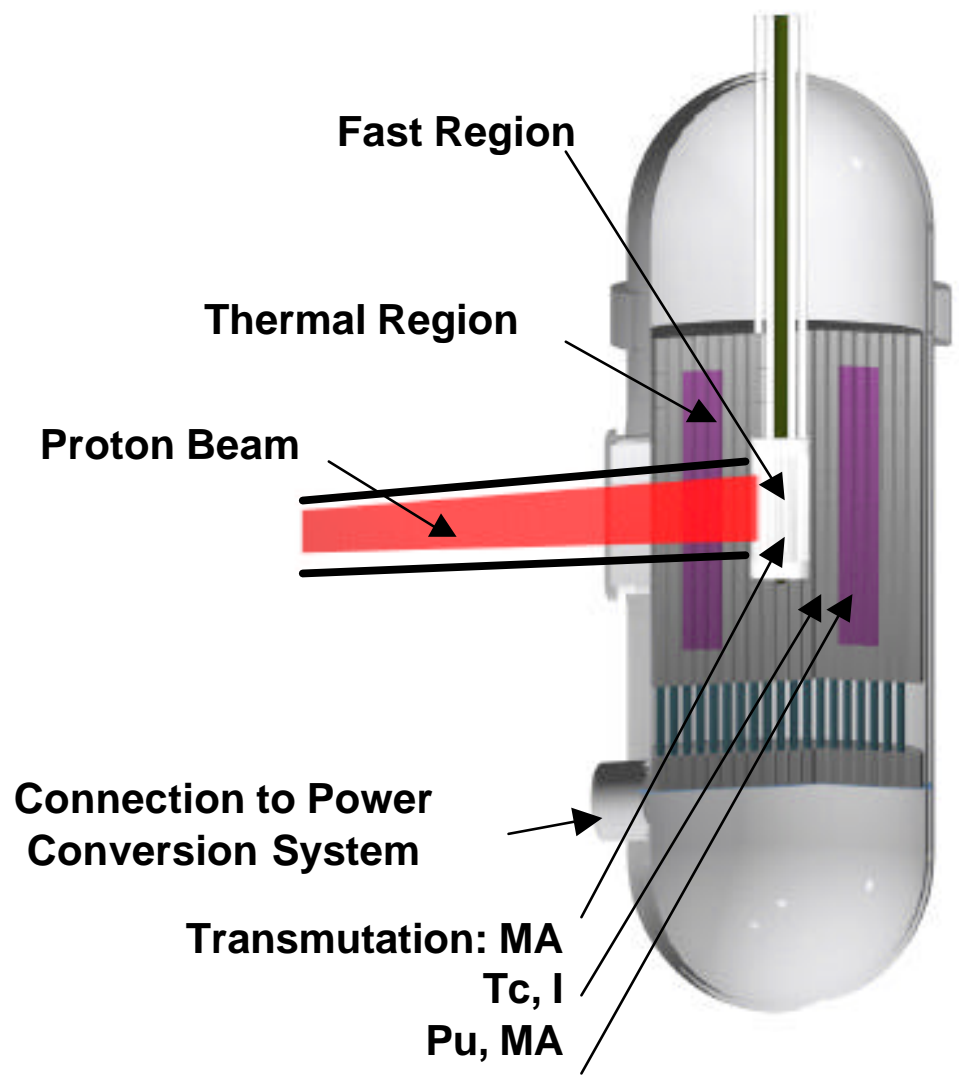

Figure 1. Thermalfast transmuter 


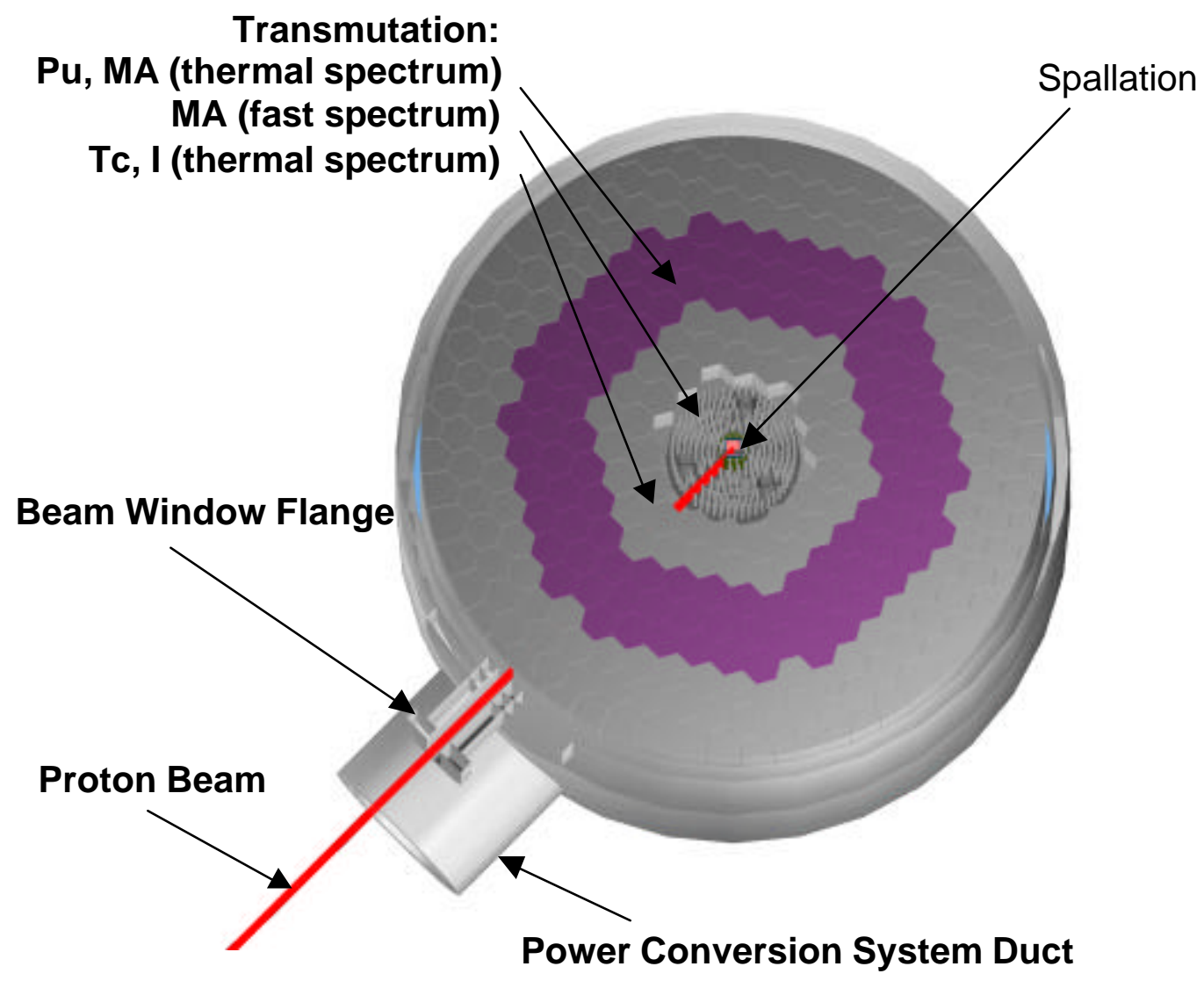

Figure 2. Thermatfast transmuter cross section 


\section{Transuranic Particles}

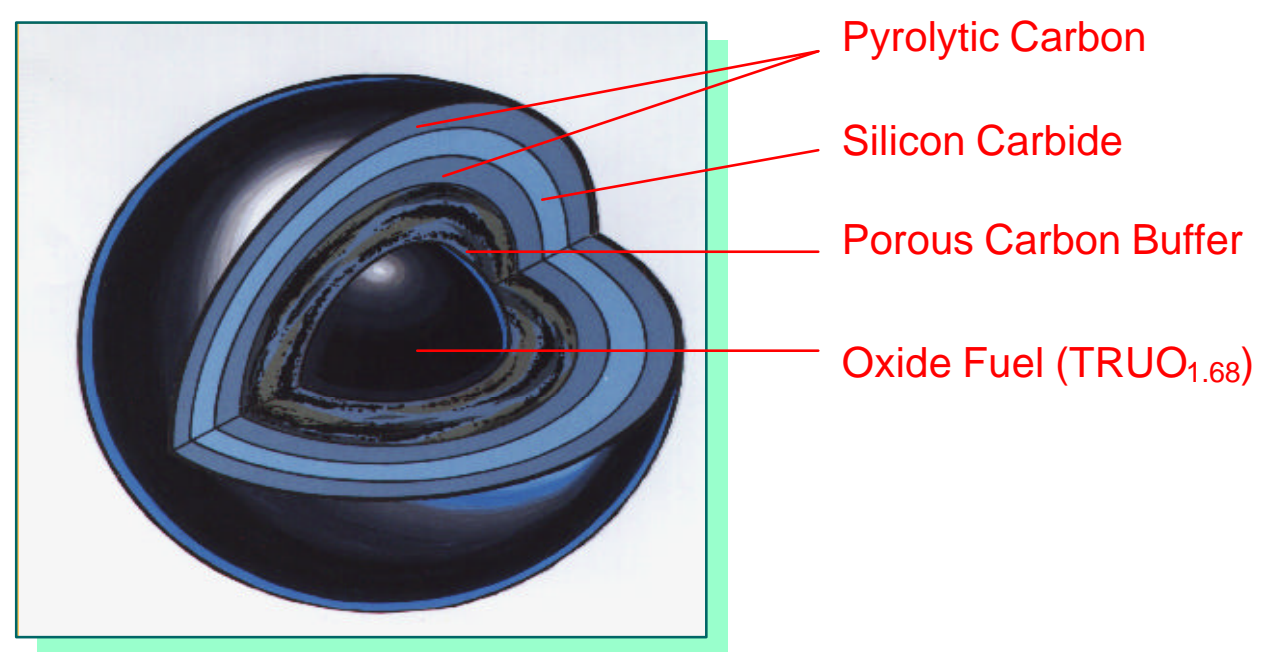

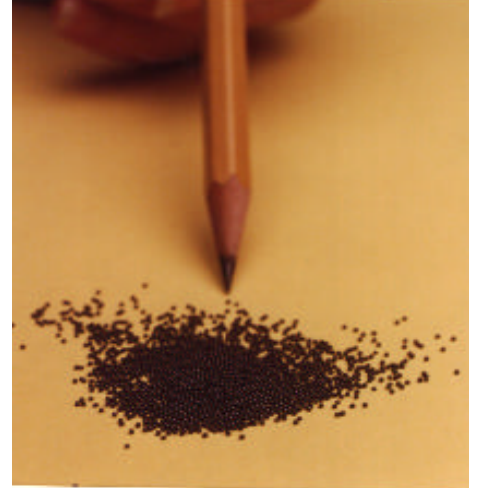

PARTICLE

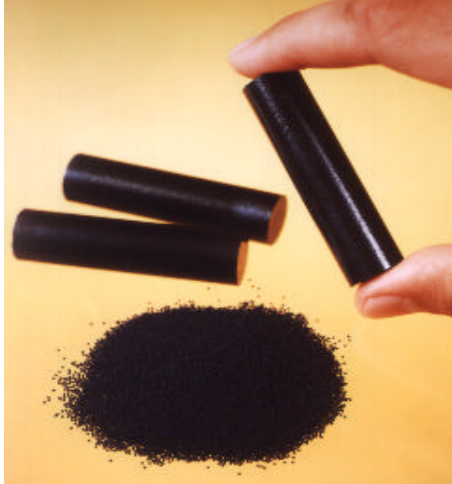

COMPACT

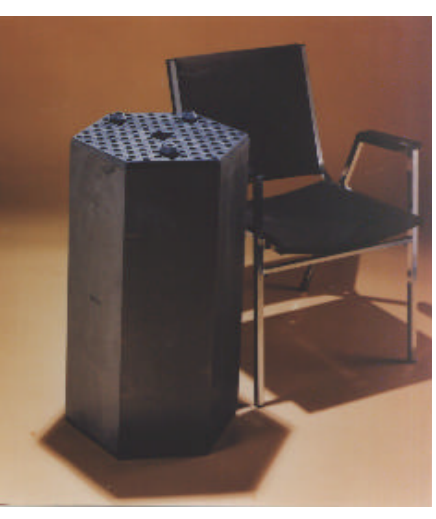

BLOCK

Figure 3. TRU particle, fuel compact, and block 


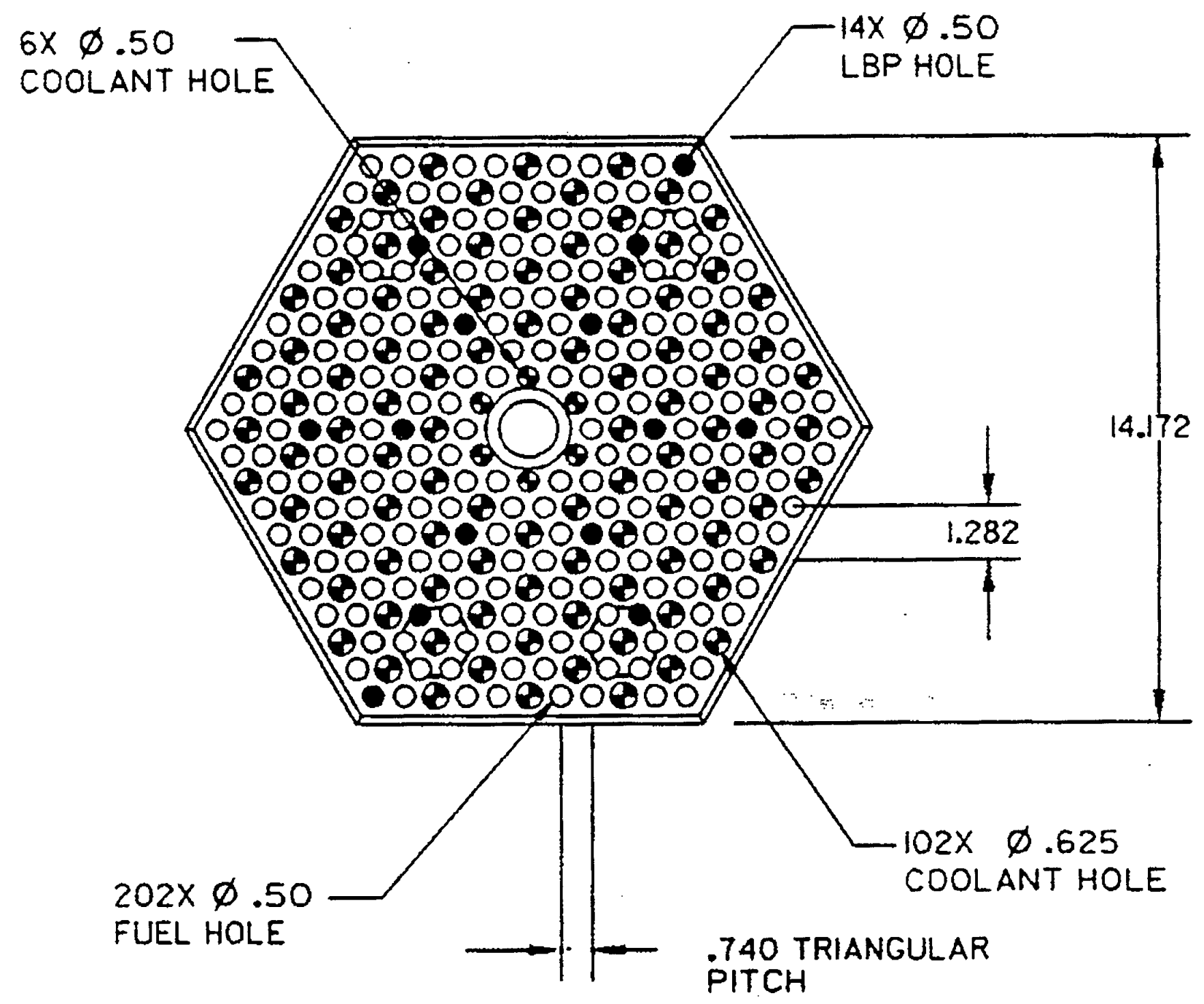

Figure 4. Cross-sectional view of the thermal block (dimensions in inches) 


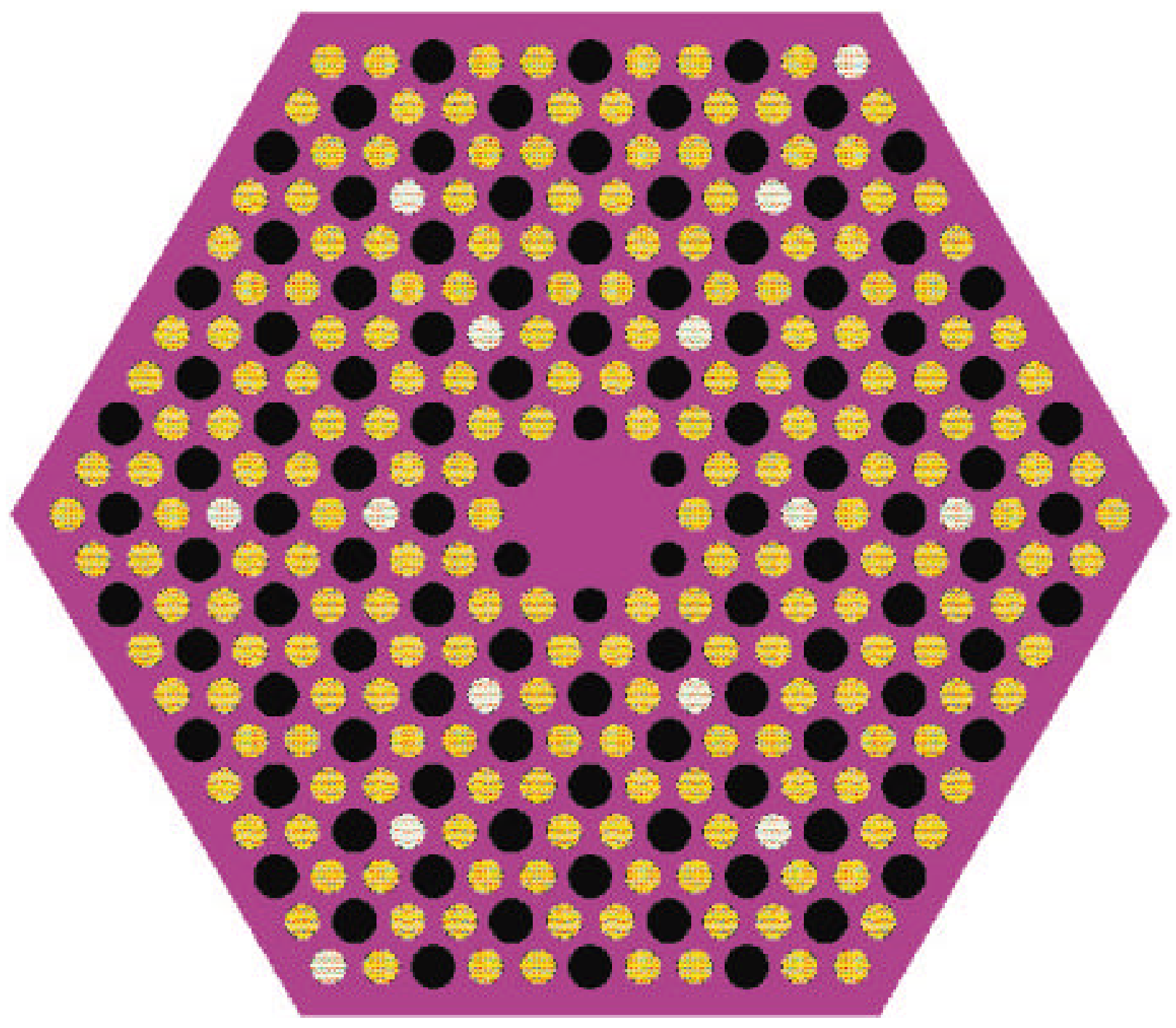

Figure 5. Thermal block model featuring coolant channels (Black color), transuranic compacts (Yellow color), and burnable poison compacts (White color) 


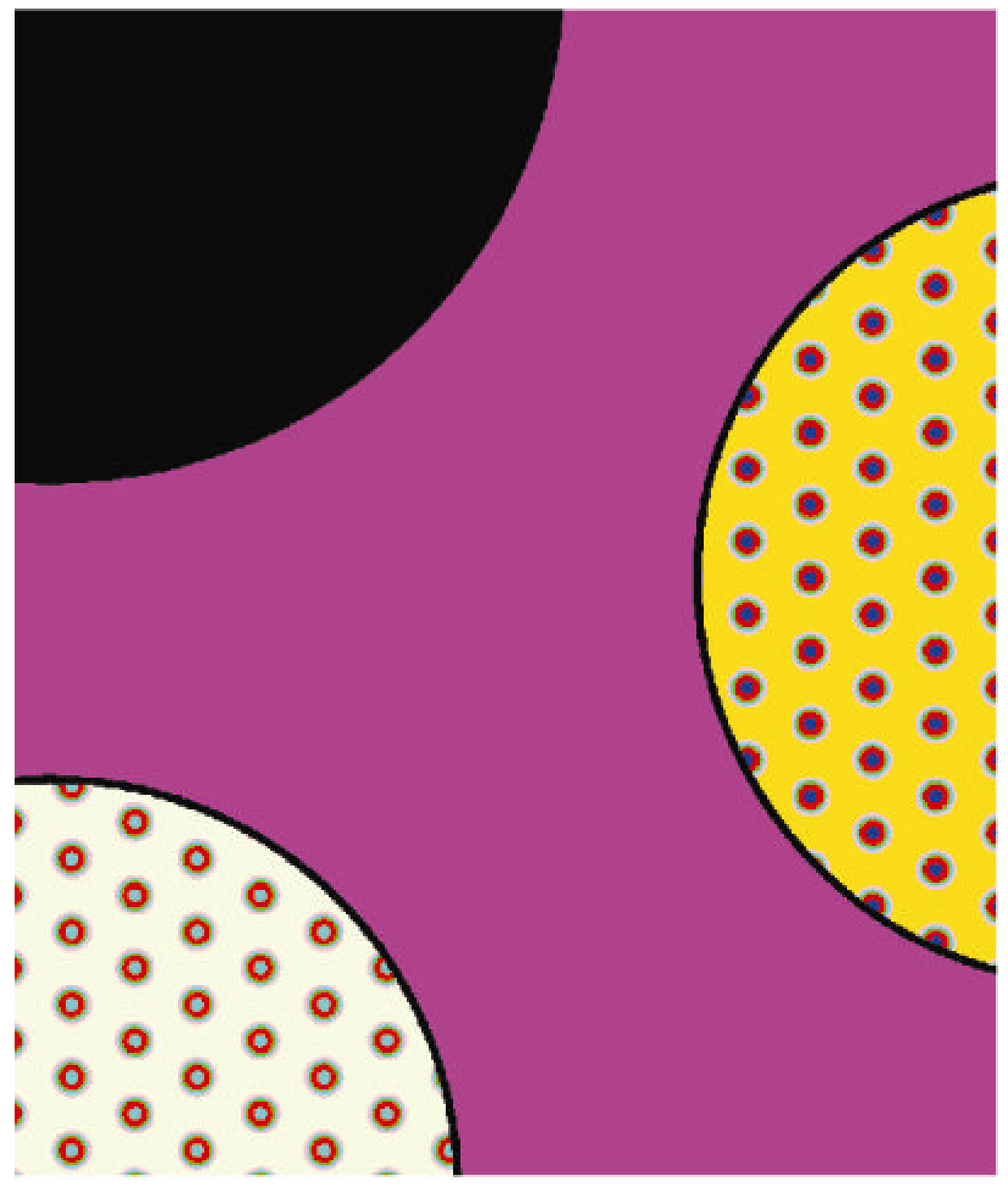

Figure 6. Enlarged block section featuring a section of the coolant channel (Top left), fuel compact (Right), and burnable poison compact (Bottom left) 


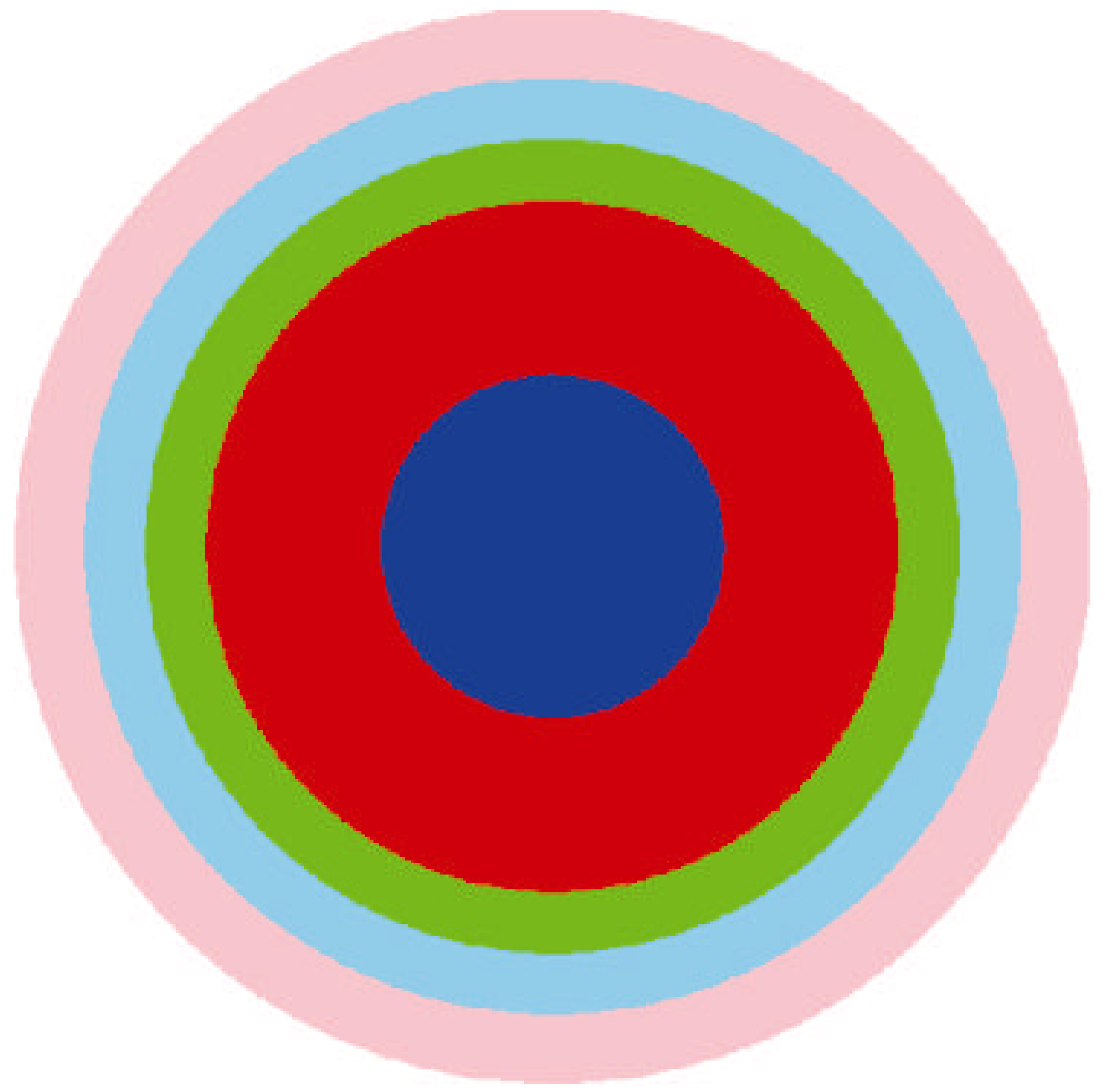

Figure 7. TRU particle model showing the five materials of each particle, transuranic oxide, porous carbon buffer, Inner pyrolytic carbon, silicon carbide, and outer pyrolytic carbon 


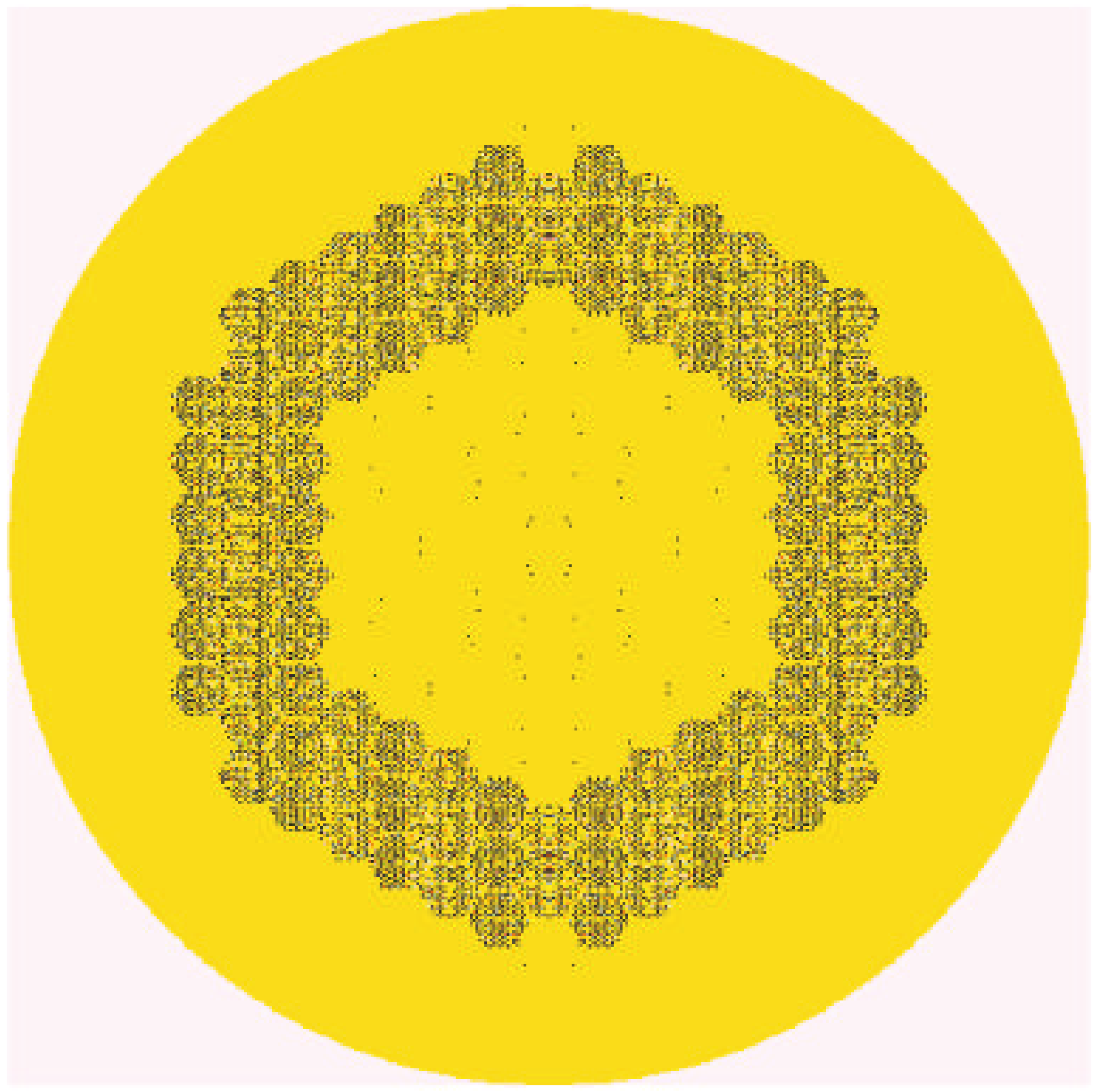

Figure 8. Horizontal cross section of the MONK transmuter model 


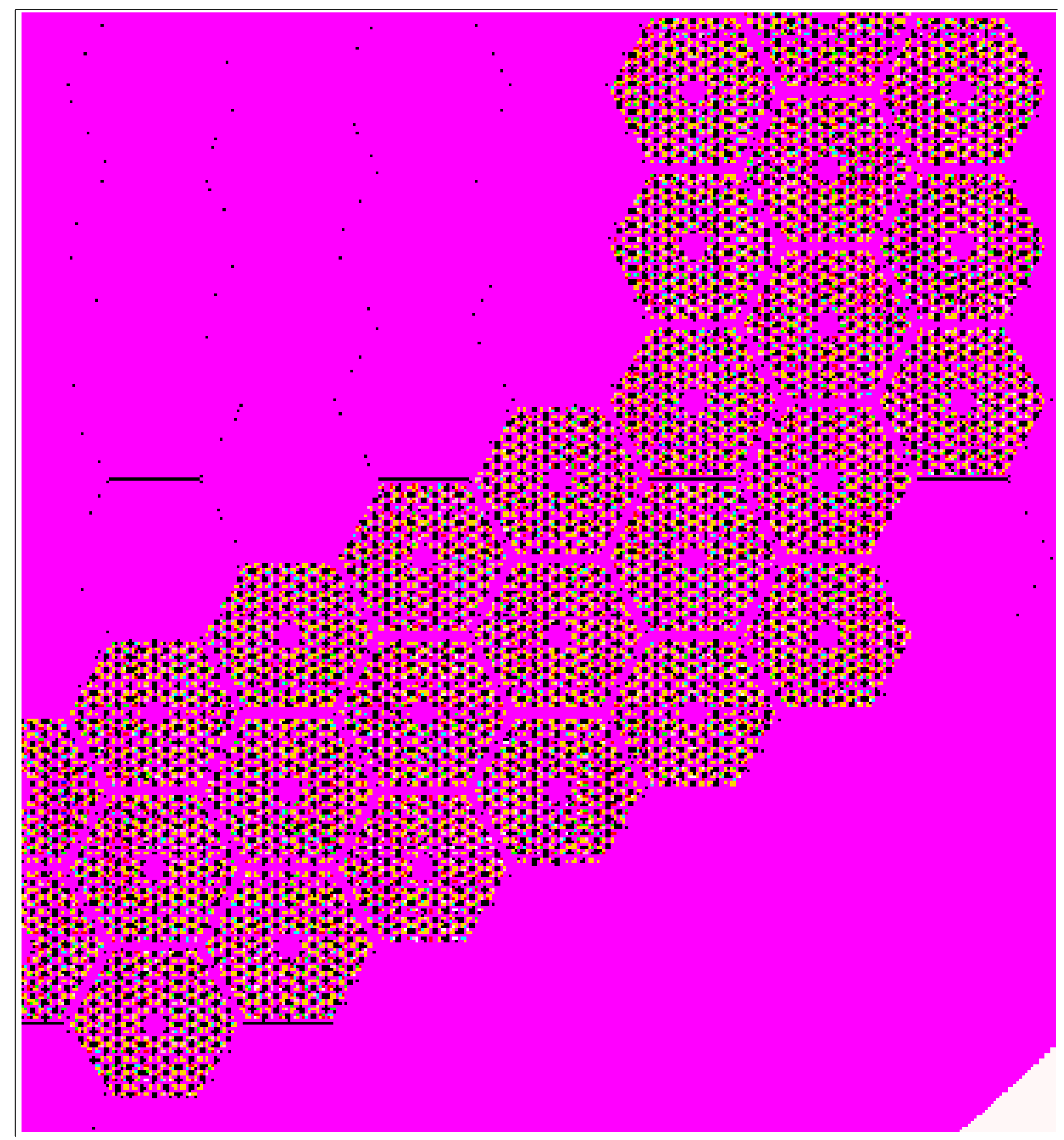

Figure 9. Enlarged section of the MONK transmuter model 


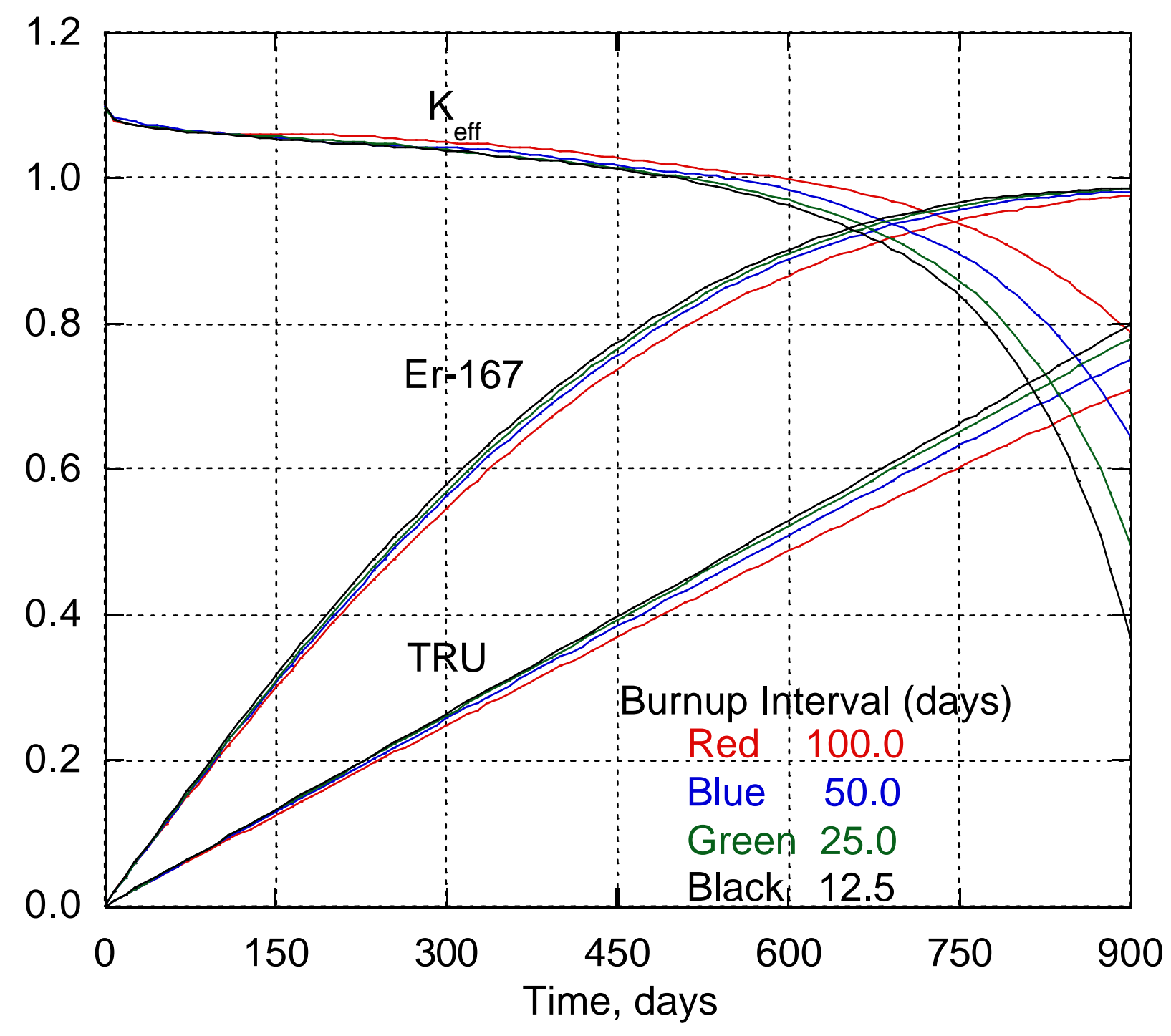

Figure 10. Main burnup parameters as a function of the operating time for different burnup intervals 


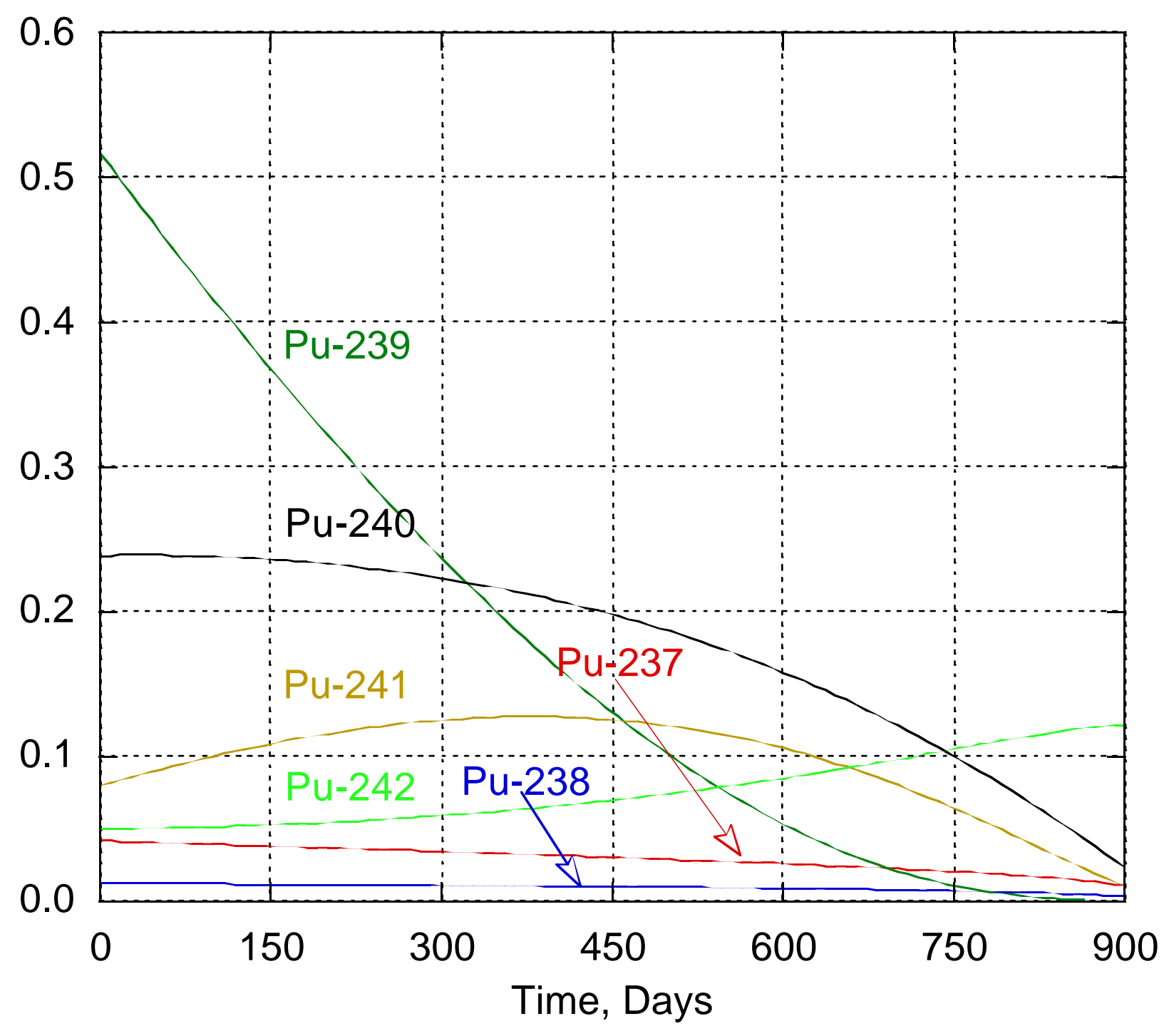

Figure 11. Relative atomic concentrations of the plutonium isotopes as a function of the operating time 


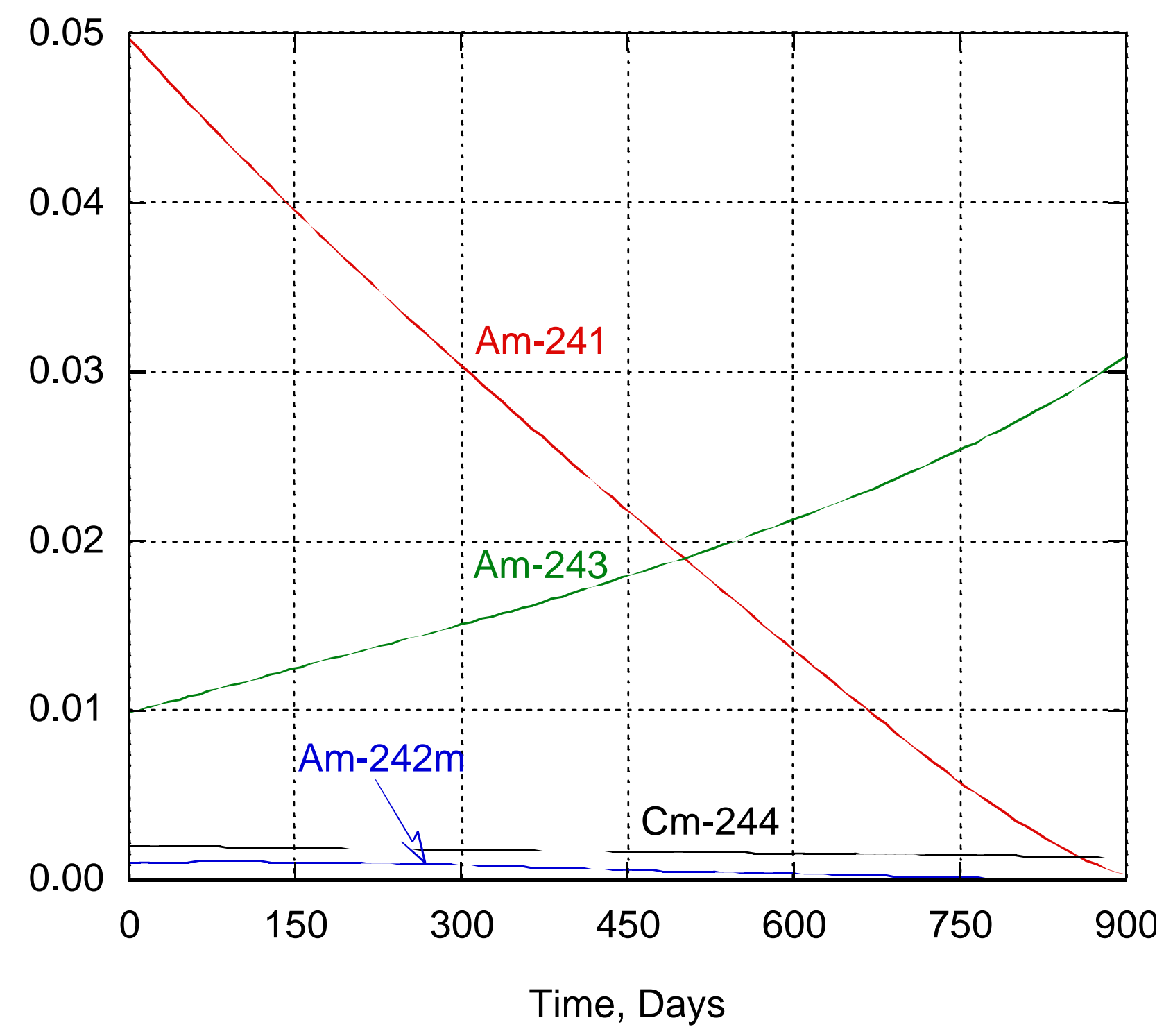

Figure 12. Relative atomic concentrations of the americium and curium-244 isotopes as a function of the operating time 


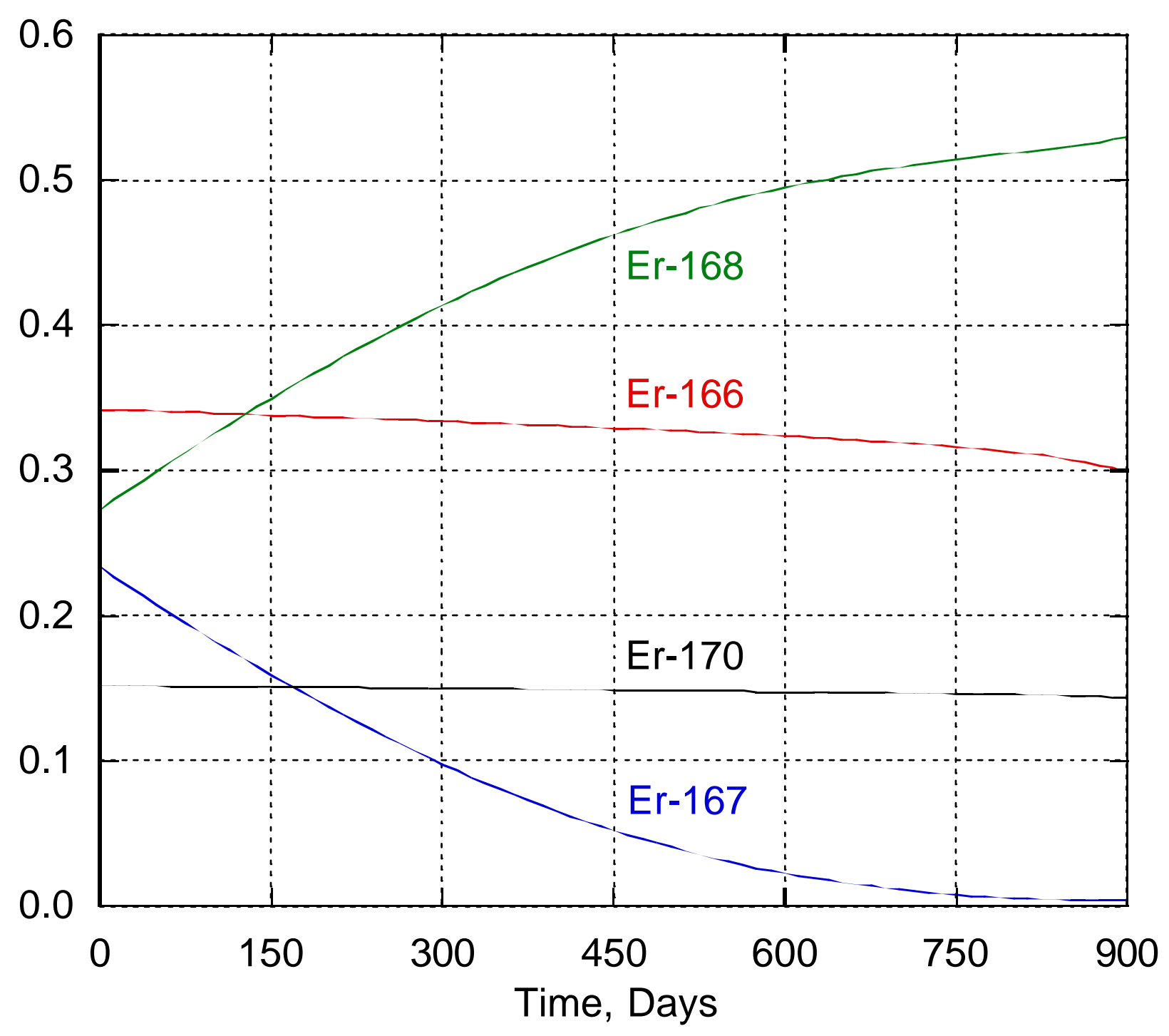

Figure 13. Relative atomic concentrations of the erbium isotopes as a function of the operating time 


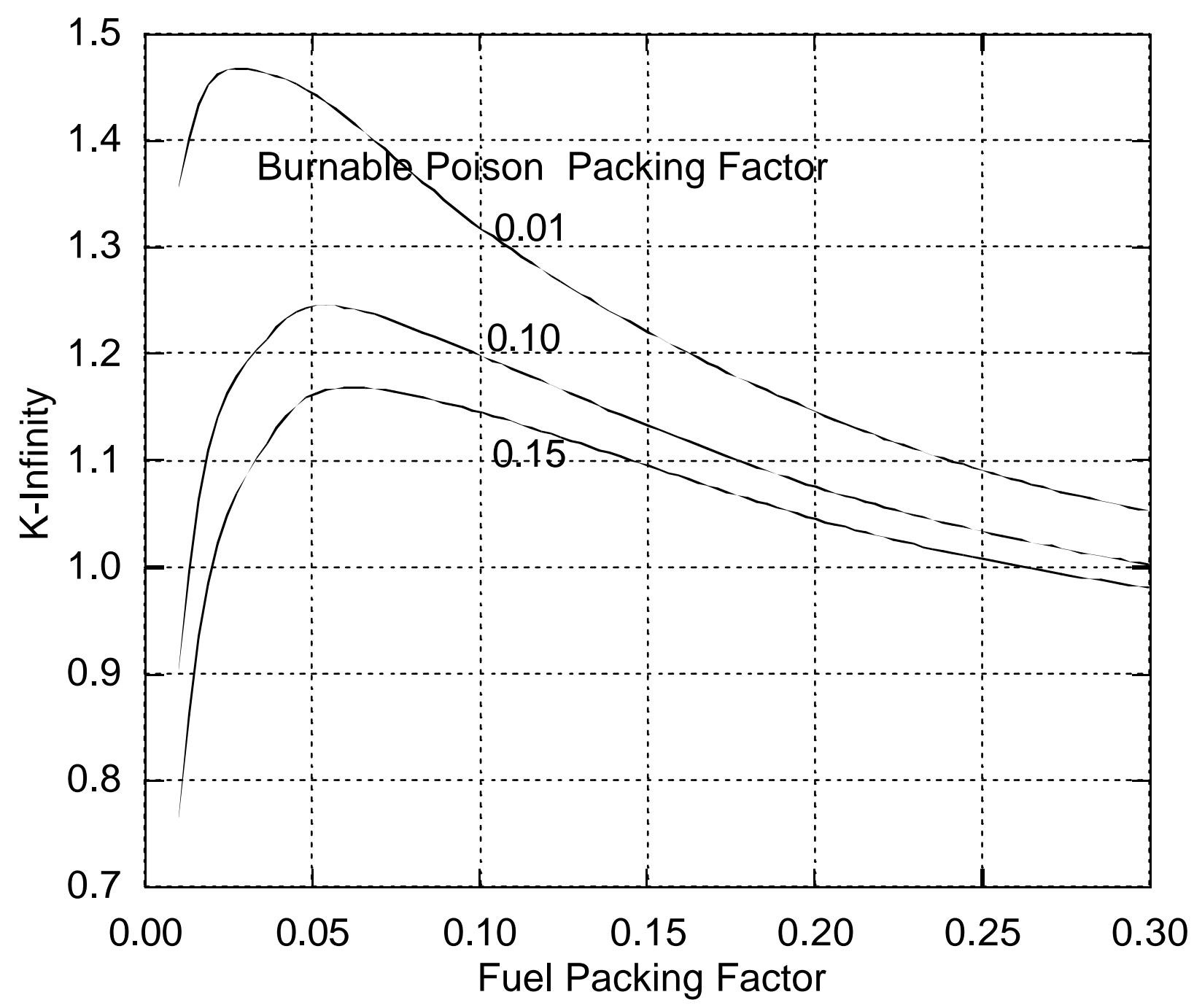

Figure 14. Block $\mathrm{K}_{\infty}$ as a function of the fuel-packing factor for different burnable poison packing factors 
Table I. Particle parameters

\begin{tabular}{|c|c|}
\hline Parameter & Value \\
\hline \multicolumn{2}{|l|}{ TRU Kernel Properties } \\
\hline Form, Density & $\mathrm{TRUO}_{1.7}, 10.2 \mathrm{~g} / \mathrm{cc}$ \\
\hline Diameter & $200 \mu \mathrm{m}$ \\
\hline \multicolumn{2}{|l|}{ TRU Particle Coating Properties } \\
\hline Buffer, Density & $100 \mu \mathrm{m}, 1.00 \mathrm{~g} / \mathrm{cc}$ \\
\hline Inner Dense PyC, Density & $35 \mu \mathrm{m}, 1.87 \mathrm{~g} / \mathrm{cc}$ \\
\hline SiC, Density & $35 \mu \mathrm{m}, 3.20 \mathrm{~g} / \mathrm{cc}$ \\
\hline Outer Dense PyC, Density & $40 \mu \mathrm{m}, 1.83 \mathrm{~g} / \mathrm{cc}$ \\
\hline Particle Diameter & $620 \mu \mathrm{m}$ \\
\hline \multicolumn{2}{|l|}{ Erbium Kernel Properties } \\
\hline Form, Density & $\mathrm{Er}_{2} \mathrm{O}_{3}, 8.64 \mathrm{~g} / \mathrm{cc}$ \\
\hline Diameter & $400 \mu \mathrm{m}$ \\
\hline \multicolumn{2}{|l|}{ Erbium Particle Coating Properties } \\
\hline Buffer, Density & $100 \mu \mathrm{m}, 1.00 \mathrm{~g} / \mathrm{cc}$ \\
\hline Inner Dense PyC, Density & $35 \mu \mathrm{m}, 1.87 \mathrm{~g} / \mathrm{cc}$ \\
\hline SiC, Density & $35 \mu \mathrm{m}, 3.20 \mathrm{~g} / \mathrm{cc}$ \\
\hline Outer Dense PyC, Density & $40 \mu \mathrm{m}, 1.83 \mathrm{~g} / \mathrm{cc}$ \\
\hline Particle Diameter & $820 \mu \mathrm{m}$ \\
\hline \multicolumn{2}{|l|}{ TRU Heavy Metal Composition } \\
\hline Np-237 & $4.10 \%$ \\
\hline Pu-238 & $1.20 \%$ \\
\hline Pu-239 & $51.55 \%$ \\
\hline Pu-240 & $23.88 \%$ \\
\hline Pu-241 & $7.99 \%$ \\
\hline Pu-242 & $5.00 \%$ \\
\hline Am-241 & $5.00 \%$ \\
\hline Am-242M & $0.10 \%$ \\
\hline Am-243 & $1.00 \%$ \\
\hline $\mathrm{Cm}-242$ & $0.00 \%$ \\
\hline $\mathrm{Cm}-243$ & $0.00 \%$ \\
\hline $\mathrm{Cm}-244$ & $0.20 \%$ \\
\hline $\mathrm{Cm}-245$ & $0.00 \%$ \\
\hline \multicolumn{2}{|l|}{ Configuration Temperatures } \\
\hline Average Thermal Assembly TRU Temperature & $770^{\circ} \mathrm{C}$ \\
\hline Temperature Operating Range & $580^{\circ} \mathrm{C}$ to $1250^{\circ} \mathrm{C}$ \\
\hline Average Graphite Temperature & $700^{\circ} \mathrm{C}$ \\
\hline Average Fast Assembly Fuel Temperature & $770^{\circ} \mathrm{C}$ \\
\hline \multicolumn{2}{|l|}{ Thermal Assembly TRU Element Data } \\
\hline TRU Element Pitch (includes gaps) & $36.1 \mathrm{~cm}$ \\
\hline TRU Element Height & $79.3 \mathrm{~cm}$ \\
\hline Graphite Block Density & $1.74 \mathrm{~g} / \mathrm{cc}$ \\
\hline Number of TRU and BP Holes & 216 \\
\hline Hole Diameter & $1.27 \mathrm{~cm}$ \\
\hline Compact Diameter & $1.2446 \mathrm{~cm}$ \\
\hline \multicolumn{2}{|l|}{ Coolant Holes } \\
\hline Number of Inner/Outer Holes & $6 / 102$ \\
\hline Diameter Inner/Outer Holes & $1.27 / 1.5875 \mathrm{~cm}$ \\
\hline
\end{tabular}


Table II. Compact heterogeneity effect

\begin{tabular}{|l|c|c|c|c|c|c|}
\hline \multirow{2}{*}{ Computer Code } & \multicolumn{2}{c|}{ MONK $^{1}$} & \multicolumn{2}{c|}{ MONK $^{2}$} & \multicolumn{2}{c|}{ DRAGON } \\
\hline \multicolumn{1}{|c|}{ Model } & $\mathrm{k}_{\infty}$ & $\Delta \mathrm{k}_{\infty} / \mathrm{k}_{\infty}, \%$ & $\mathrm{k}_{\infty}$ & $\Delta \mathrm{k}_{\infty} / \mathrm{k}_{\infty}, \%$ & $\mathrm{k}_{\infty}$ & $\Delta \mathrm{k}_{\infty} / \mathrm{k}_{\infty}, \%$ \\
\hline Explicit Modeling & 1.2764 & -- & 1.2534 & -- & 1.2539 & - \\
\hline Homogenized Particles & 1.1101 & -13.02 & 1.1004 & -12.21 & -- & - \\
\hline Homogenized compact & 1.0928 & -14.38 & 1.0847 & -13.46 & 1.0778 & -14.05 \\
\hline
\end{tabular}

1 Quasi-continuous energy library

2 Multigroup library (172 group) 
Table III. MONK burnable poison heterogeneity effect

\begin{tabular}{|l|c|c|}
\hline \multicolumn{1}{|c|}{ Burnable Poison Model } & $\mathrm{k}_{\infty}$ & $\Delta \mathrm{k}_{\infty} / \mathrm{k}_{\infty}, \%$ \\
\hline Explicit Modeling & 1.1864 & \\
\hline Homogenized Particles & 1.1649 & -1.81 \\
\hline Homogenized Compact & 1.1604 & -2.19 \\
\hline
\end{tabular}


Table IV. Impact of different nuclear data libraries on monk block results

\begin{tabular}{|c|c|c|}
\hline Nuclear Data Base & $\begin{array}{c}\text { Number of Energy } \\
\text { Groups }\end{array}$ & $\mathrm{K}_{\infty}$ \\
\hline ENDF/B-VI & 13193 & 1.2761 \\
\hline JEF2.2 & 13193 & 1.2764 \\
JEF2.2 & 8220 & 1.2658 \\
\hline JEF2.2 & 172 & 1.2534 \\
JEF2.2 & 69 & 1.2510 \\
\hline
\end{tabular}


Table V. Temperature effect on the block performance

\begin{tabular}{|l|c|c|}
\hline \multicolumn{1}{|c|}{ Burnable Poison Model } & $\mathrm{K}_{\infty}$ & Relative Difference, $\%$ \\
\hline Cold Conditions & 1.1327 & \\
\hline Hot Fuel Particles & 1.1112 & -1.90 \\
\hline Hot Compact & 1.0954 & -3.29 \\
\hline Hot Block & 1.0562 & -6.75 \\
\hline
\end{tabular}


Table VI. Percentage differences in the compact power distribution from DRAGON and MONK relative to MONK results for half block

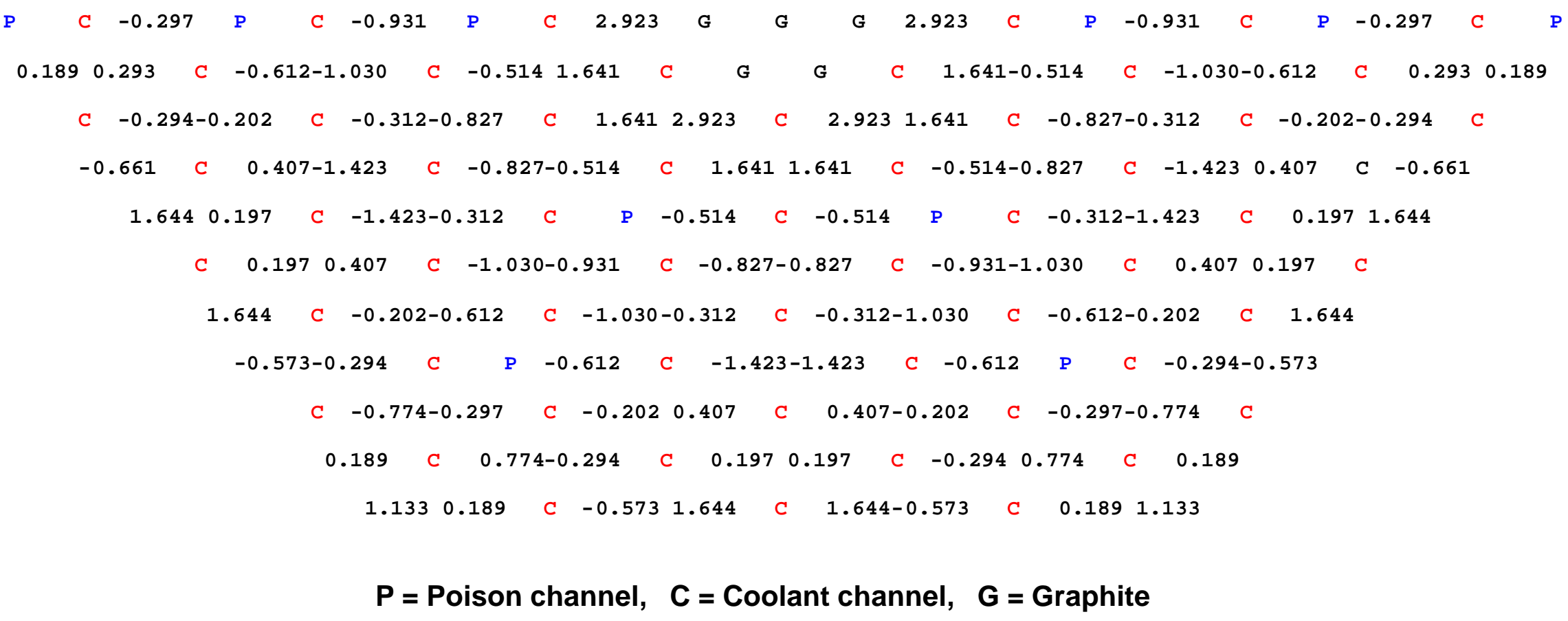


Table VII. Core power distribution and the percentage differences between DRAGON and MONK relative to MONK results for sixty-degree sector

\section{Monk core results}

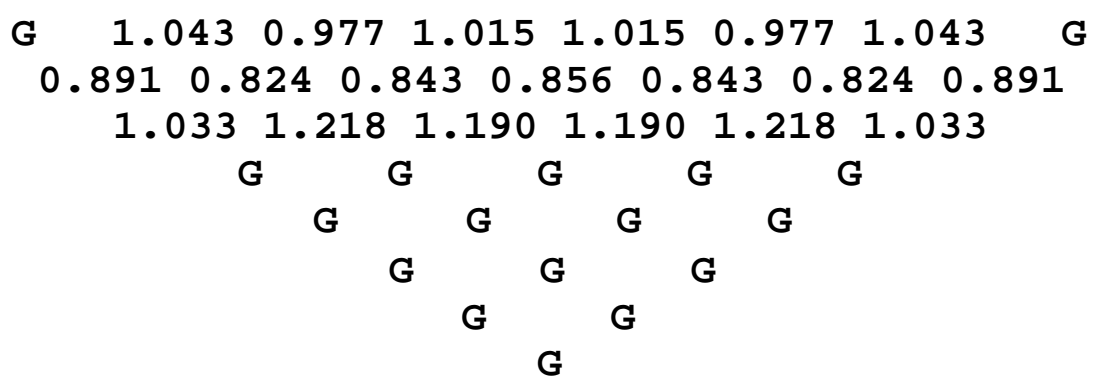

\section{DIF3D core results}

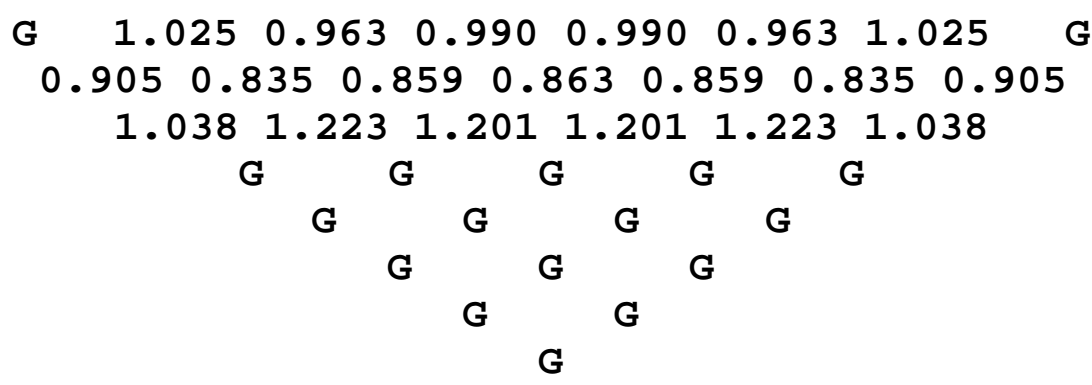

Percentage differences relative to MONK results

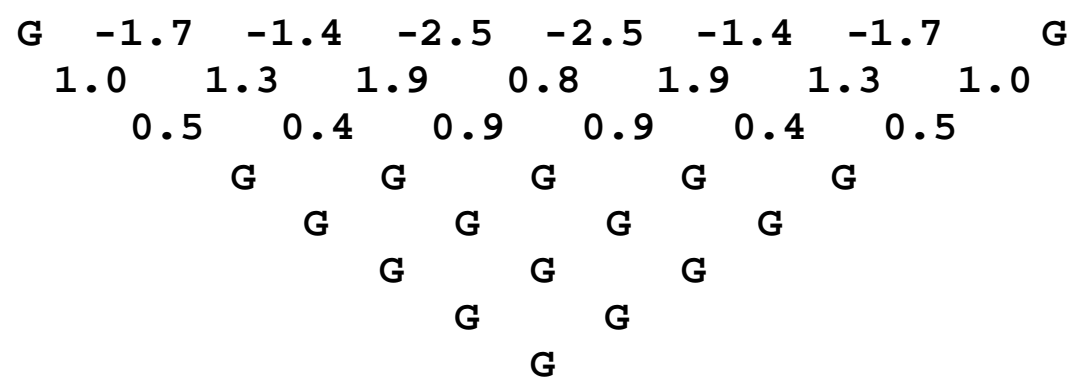

$\mathrm{G}=$ Graphite block 


\section{REFERENCES}

1. Private Communications, General Atomics, March 2000.

2. Y. Gohar, T. A. Taiwo, J. E. Cahalan, and P. J. Finck, "Assessment of the General Atomics Accelerator Transmutation of Waste Concept Based on the Gas-TurbineModular Helium Cooled Reactor Technology," Argonne National Laboratory Report, ANL/TD/TM 01-16, 2000.

3. T. A. Taiwo, Y. Gohar, and P. J. Finck, "Core Physics Performance of Recycled LWR-Discharge-TRU Oxide Fuel in a GT/AD-MHR," Proceeding Of the IAEA meeting on Core Physics and Engineering Aspects of Emerging Nuclear Energy Systems for Energy Generation and Transmutation Meeting, Argonne National Laboratory, Argonne, November 28- December 1, 2000.

4. T. A. Taiwo, Y. Gohar and P. J. Finck, "ASSESSMENT OF THE TELEDIAL GASCOOLED TRANSMUTER CONCEPT," 2000 ANS/ENS International Meeting, Washington, DC, November 12-16, 2000.

5. Y. Gohar, T. A. Taiwo, C. G. Stenberg, P. J. Finck, "Verification of Physics Predictions for GT/AD-MHR Core Designs," 2000 ANS/ENS International Meeting, Washington, DC, November 12-16, 2000.

6. The ANSWERS Software Package, MONK - A Monte Carlo Program for Nuclear Criticality Safety and Reactor Physics Analyses, User Guide for Version 8, ANSWERS/MONK(98)6, AEA Technology, UK.

7. G. MARLEAU et al., "A User's Guide for DRAGON," IGE-174, Rev. 3, Ecole Polytechnique de Montreal (Dec. 1997).

8. K. L. DERSTINE, "DIF3D: A Code to Solve One-, Two-, and Three-Dimensional Diffusion Theory Problems," ANL-82-64, Argonne National Laboratory, (1984).

9. W. S. Yang and H. Khalil, "Analysis of the ATW Fuel Cycle Using the REBUS-3 Code System," Trans. Am. Nucl. Soc., 81, 277 (1999).

10.Y. Gohar, T. A. Taiwo, and P. J. Finck, "Transmutation of Light Water ReactorDischarge-Transuranics in a High Temperature Gas Cooled Reactor," Accelerator Applications/Accelerator Driven Transmutation Technology and Applications 01 (AccApp-ADTTA'01), Reno, Nevada, November 11-15,2001. 


\section{DISTRIBUTION LIST FOR ANL/TD/TM01-17}

\section{$\underline{\text { Internal }}$}

R. K. Ahluwalia

R. Hill

C. Reed

S. K. Bhattacharyya

H. Khalil

J. Roglans

M. Billone

J. Laidler

A. B. Smith

J. Brooks

J. Liaw

D. L. Smith

J. Cahalan

Y. Chang

S. Majumdar

T. Taiwo (10)

D. Crawford

V. Maroni

R. Valentin

D. Ehst

R. McKnight

D. Wade

P. Finck (10)

J. Herczeg

D. Weber

E. Fujita

L. LeSage

R. W. Weeks

R. Mattas

Y. Gohar (10)

K. Natesan

M. Williamson

J. Herczeg

P. Persiani

T. Yule

D. Hill

B. Picologlou

FPP Files

TIS

\section{External}

ANL-E Library

ANL-W Library

DOE/OSTI (2)

E. Adamov, Research and Development Institute of Power Engineering, Moscow, Russia

J. Anderson, Los Alamos National Laboratory, Los Alamos, NM

E. Arther, Los Alamos National Laboratory, Los Alamos, NM

R. Aymar, ITER Garching, Garching, Germany

C. Baker, University of California, San Diego, CA

D. Baldwin, General Atomic, San Diego, CA

C. G. Bathke, Los Alamos National Laboratory, Los Alamos, NM

A. Baxter, General Atomics, San Diego, CA

D. R. Bennett, Los Alamos National Laboratory, Los Alamos, NM

S. Berk, U.S. Department of Energy, Germantown, MD

E. E. Bloom, Oak Ridge National Laboratory, Oak Ridge, TN

C. Bolton, U.S. Department of Energy, Germantown, MD

M. Cappiello, Los Alamos National Laboratory, Los Alamos, NM

E. Cheng, TSI Research Inc., San Diego, CA

V. Chernov, Bochvar Research Institute of Inorganic Materials, Moscow, Russia

V. Chuyanov, ITER Garching, Garching, Germany

R. Conn, University of California, San Diego, CA

R. Dagazian, U.S. Department of Energy, Germantown, MD

J. Davis, The Boeing Company, St. Louis, MO

W. Dove, U.S. Department of Energy, Germantown, MD

M. Eid, CEA, Gif-sur-Yvette, France 
L. El-Guebaly, University of Wisconsin, Madison, WI

G. Emmert, University of Wisconsin, Madison, WI

V. Evtikhin, State Enterprise Red Star, Moscow, Russia

O. Filatov, Efremov Scientific Research Institute, St. Petersburg, Russia

U. Fischer, Forschungsze ntrum Karlsruhe, Germany

M. Fuetterer, CEA, Gif-sur-Yvette, France

W. Gauster, Sandia National Laboratories, Albuquerque, NM

M. Gasparotto, ENEA, Frascati, Italy

J. Gilleland, Archimedes Technology Group, Inc., San Diego, Ca

L. Giancarli, CEA, Gif-sur-Yvette, France

F. Goldner, Department of Energy, Germantown, MD

R. Goldston, Princeton Plasma Physics Laboratory, Princeton, NJ

J. Gulliford, AEA Technology, United Kingdom

W. G. Halsely, Los Alamos National Laboratory, Los Alamos, NM

G. Heusener, Forschungsze ntrum Karlsruhe, Karlsruhe, Germany

H. Kawamura, Japan Atomic Energy Research Institute, Oarai, Japan

V. Kirillov, Efremov Scientific Research Institute, St. Petersburg, Russia

J. U. Knebel, Forschungszentrum Karlsruhe, Karlsruhe, Germany

R. A. Krakowski, Los Alamos National Laboratory, Los Alamos, NM

G. Kulcinski, University of Wisconsin, Madison, WI

I. Lyublinski, State Enterprise Red Star, Moscow, Russia

H. Maekawa, Japan Atomic Energy Research Institute, Japan

S. Malang, Forschungszentrum Karlsruhe, Karlsruhe, Germany

D. Markovskij, Kurchatov Institute, Moscow Russia

W. Marton, U.S. Department of Energy, Germantown, MD

Y. Martynenko, Kurchatov Institute, Moscow, Russia

R. Matera, URC-IHCP, Ispra, Italy

S. Matsuda, Japan Atomic Energy Research Institute, Naka, Japan

B. Matthews, Los Alamos National Laboratory, Los Alamos, NM

K. McCarthy, Idaho National Engineering and Environmental Laboratory, Idaho Falls, ID

R. Miller, University of California, San Diego, CA

R. Moir, Lawrence Livermore National Laboratory, Livermore, CA

F. Najmabadi, University of California, San Diego, CA

R. Nygren, Sandia National Laboratories, Albuquerque, NM

A. Opdenaker, U.S. Department of Energy, Germantown, MD

R. Parker, Massachusetts Institute of Technology, Cambridge. MA

K. Pasamehmetoglu, Los Alamos National Laboratory, Los Alamos, NM

J. Perkins, Lawrence Livermore National Laboratory, Livermore, CA

D. Petti, Idaho National Engineering and Environmental Laboratory, Idaho Falls, ID

E. J. Pitcher, Los Alamos National Laboratory, Los Alamos, NM

S. Piet, Idaho National Engineering and Environmental Laboratory, Idaho Falls, ID

D. Post, Lawrence Livermore National Laboratory, Livermore, CA

J. Raeder, ITER Garching, Garching, Germany

C. Rodriguez, General Atomics, San Diego, CA

M. Salvatores, CEA Cadarache, France

M. Sawan, University of Wisconsin, Madison, WI 
F. Scaffidi-Argentina, EFDA Close Support Unit, Culham Science Centre, United Kingdom

K. Schultz, General Atomic, San Diego, CA

T. Shannon, University of Tennessee, Knoxville, TN

G. Shatalov, Kurchatov Institute of Atomic Energy, Moscow, Russia

R. Sheffield, Los Alamos National Laboratory, Los Alamos, NM

M. Solonin, Bochvar Research Institute of Inorganic Materials, Moscow, Russia

W. M. Stacey, Georgia Institute of Technology, Atlanta, GA

T. Schulenberg, Forschungszentrum Karlsruhe, Karlsruhe, Germany

Yu. A. Sokolov, Ministry of Atomic Power, Moscow, Russia

D. Steiner, Rensselaer Polytechnic Institute, Troy, NY

Y. Strebkov, Research and Development Institute of Power Engineering, Moscow, Russia

K. Sumita, Osaka University, Osaka, Japan

I. Sviatoslavsky, University of Wisconsin, Madison, WI

H. Takatsu, Japan Atomic Energy Research Institute, Tokyo, Japan

A Takahashi, Osaka University, Osaka, Japan

D. Thome, General Atomic, San Diego, CA

M. Tillack, University of California, San Diego, CA

M. Todosow, Brookhaven National Laboratory, Upton, L.I., NY

$\mathrm{H}$. Trellue, Los Alamos National Laboratory, Los Alamos, NM

G. J. Van Tuyle, Los Alamos National Laboratory, Los Alamos, NM

J. Van der Laan, NRG Petten, Petten, The Netherlands

E. P. Velikov, Kurchatov Institute of Atomic Energy, Moscow, Russia

Laurie Waters, Los Alamos National Laboratory, Los Alamos, NM

C. Wong, General Atomics, San Diego, CA

H. Yoshida, ITER Naka, Naka, Japan

C.E.A. Library, Fontenay-aux-Roses, France

Librarian, Culham Laboratory, England

Thermonuclear Library, Japan Atomic Energy Research Institute, Japan

University of Illinois, Fusion Studies Laboratory

University of Illinois, Grainger Engineering Library Information Center 